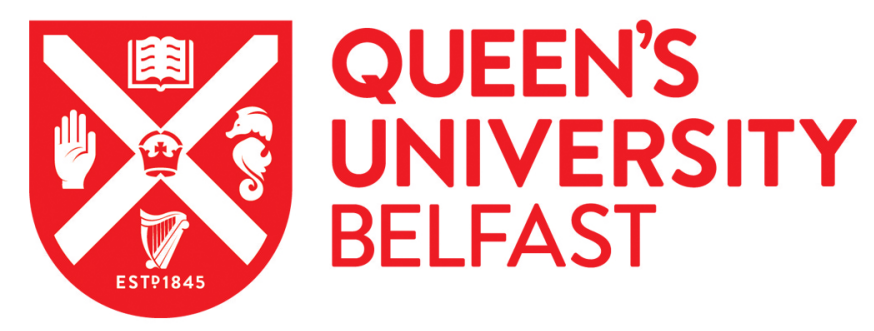

\title{
Sensitivity-based dispatch of DG for voltage control
}

Abbott, S. R., Fox, B., \& Morrow, D. J. (2014). Sensitivity-based dispatch of DG for voltage control. In 2014 IEEE PES General Meeting / Conference \& Exposition (Vol. 2014-October). Institute of Electrical and Electronics Engineers Inc.. https://doi.org/10.1109/PESGM.2014.6939175

Published in:

2014 IEEE PES General Meeting | Conference \& Exposition

Document Version:

Publisher's PDF, also known as Version of record

Queen's University Belfast - Research Portal:

Link to publication record in Queen's University Belfast Research Portal

Publisher rights

(02014 IEEE.

This work is made available online in accordance with the publisher's policies. Please refer to any applicable terms of use of the publisher.

\section{General rights}

Copyright for the publications made accessible via the Queen's University Belfast Research Portal is retained by the author(s) and / or other copyright owners and it is a condition of accessing these publications that users recognise and abide by the legal requirements associated with these rights.

Take down policy

The Research Portal is Queen's institutional repository that provides access to Queen's research output. Every effort has been made to ensure that content in the Research Portal does not infringe any person's rights, or applicable UK laws. If you discover content in the Research Portal that you believe breaches copyright or violates any law, please contact openaccess@qub.ac.uk. 


\title{
Sensitivity-Based Dispatch of DG for Voltage Control
}

\author{
S.R. Abbott, Student Member, IEEE, B. Fox and D.J. Morrow, Member, IEEE 1
}

\begin{abstract}
The paper presents a methodology for managing a network's voltage profile by dispatching grid-connected distributed generation (DG). The coordinated voltage control algorithm has two main stages for controlling network voltages. Firstly, it avails of any available network reactive power assets and reactive power available from DG which is dispatched to coincide with network needs. If insufficent reactive power is available from the DG units their active power may be curtailed to free up reactive power to ensure voltages are within the desired range. The paper demonstrates that the sensitivity based approach can maintain voltages within the desired range and has the potential to reduce network losses, increase network capacity to accommodate DG and to reduce the distribution network's dependence on the transmission network for reactive power.
\end{abstract}

Index Terms- Distributed power generation, power generation dispatch, reactive power control, voltage control.

\section{INTRODUCTION}

Accommodation of increased distributed generation (DG) has stressed existing networks and often requires significant network reinforcement. As DG penetration increases, the cumulative impact of many small generators can have significant effects on power quality, particularly for stochastic generation. Due to the inflexibility of the voltage control strategies on the LV and MV network, the increased penetration of $\mathrm{DG}$ can give rise to a voltage management problem for the utility. This issue can be managed to a certain extent through Distribution Codes. However, the full potential of distributed generation requires a co-ordinated approach to manage feeder voltage profiles.

The main thrust of such an approach would be to adjust generator reactive power resources to maintain all voltages within limits, without unduly affecting their operation. In extreme cases, it may be necessary to curtail active power from non-firm DG. Conversely, rather than curtailing DG, it may be possible to regulate local load, in sympathy with network requirements.

The main focus here therefore will be on reactive power control from DG and, if required, demand-side management (DSM). It is proposed that the voltages of critical nodes are monitored, and that the generators' reactive power and the apparent power of loads can be adjusted remotely.

The research reported here was funded by the EPSRC Power Networks Research Academy consortium and by Science Foundation Ireland Grant 06/CP/E002. The authors are with the Electric Power and Energy Systems Research Group at Queen's University Belfast (QUB), UK (e-mail: sabbott01@qub.ac.uk, b.fox@qub.ac.uk and dj.morrow@ee.qub.ac.uk).
The authors have developed a novel method for control of distributed generator reactive resources, aimed at maximising the connected generation capacity within network voltage limits. The method is based on the familiar Newton-Raphson load-flow equations. The paper will present the particular form of the Newton-Raphson equations found suitable for the task. The method whereby node voltages are related to reactive and active power adjustments will be explained.

The method is tested on a 13-bus IEEE Node Test Feeder network variant [1] and demonstrates the impact which DG can have on network voltages. The system-wide coordinated control strategy, considering multi-system constraints, for controlling network voltage levels within statutory limits is presented and evaluated using DIgSILENT PowerFactory [2].

\section{DG CONNECTION REQUIREMENTS AND OPERATION}

DG connected to the distribution network is known to influence short-circuit levels, reverse power flows, voltage regulation, system loading and network losses [3,4]. Distribution Codes state that the impact of connecting DG to the network should be assessed to ensure that all elements of the network function within their operational limits [5]. DG may be regulated to ensure network equipment such as transformers and conductors are operated within the elements' rated limits as expressed in equation (II.1).

$$
\boldsymbol{S}_{i}=P_{i}+\mathrm{jQ}_{\mathrm{i}} \text { where } 0 \leq \boldsymbol{S}_{i} \leq S_{\text {iMax }}
$$

Here $S_{i}$ is the apparent power (MVA), $P_{i}$ is the active power (MW), $Q_{i}$ is the reactive power (MVAr) of the element at node $i$ and $S_{\operatorname{Max}}$ is the element's maximum apparent power of the element in question.

The bus voltage at node $i, V_{i}$, must remain within the limits stated in the relevant distribution code. This depends on the operational voltage range; for the presented work the range is as expressed in equation (II.2).

$$
\begin{gathered}
0.95 p u \leq V_{i} \leq 1.05 p u \\
\text { III. CONTROL SCHEME }
\end{gathered}
$$

A coordinated control strategy is proposed here where DG is dispatched in sympathy with network requirements. For a network with fixed topology, the voltages are related to the network's active power, reactive power and loading. Management of network voltage requires adjustment of one or more of these variables. The distribution system operator (DSO) will not wish to curtail customer loads, except as a 
last resort. At present the only method of control requires non-firm generators to curtail active power if voltage at the point of connection is too high.

\section{A. Control methodology}

In the proposed control algorithm the DG with the greatest influence on nodal voltages, which are outside the sanctioned range, is adjusted. The system wide controller firstly utilises any available reactive power from the network and distributed generation and, if required, it will curtail active power to allow for greater reactive power flexibility, before consideration is given to network loading.

Figure 1 is a process flow of the control algorithm. For given network conditions the process determines if the network equipment operates within the required limits of (II.1) - (II.2). When network conditions are outside operational limits, control actions are required. The control algorithm will force generation into range. The sensitivity of network voltages to changes in reactive power, active power and load are determined. A merit order, starting with reactive power, then active power and finally load adjustment, is employed to determine which DG, load or combination should be used to support network voltages.

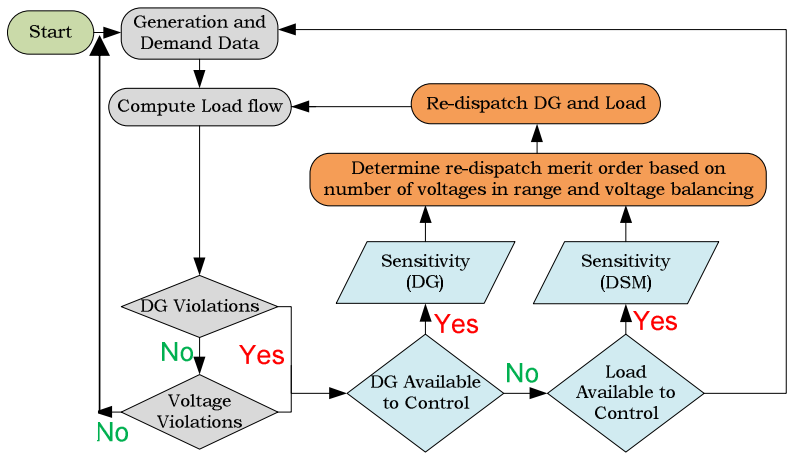

Figure 1: Simulation process flow.

\section{METHOD}

The basis for deriving DG sensitivity is the NewtonRaphson equation [6] relating active $(P)$ and reactive power $(Q)$ to node angle $(\theta)$ and voltage $(V)$ adjustments:

$$
\left[\begin{array}{l}
\Delta P \\
\Delta Q
\end{array}\right]=\left[\begin{array}{ll}
\mathrm{J}_{1} & \mathrm{~J}_{2} \\
\mathrm{~J}_{3} & \mathrm{~J}_{4}
\end{array}\right]\left[\begin{array}{l}
\Delta \theta \\
\Delta V
\end{array}\right]
$$

It is shown in $[7,8]$ that the Newton-Raphson formulation can be rearranged to relate node voltage sensitivity to reactive and active power injections by equations (IV.2) and (IV.3). The sensitivity relates how changes in reactive and active power injected into the system at a particular node affects the voltage levels at all remaining nodes on the network, assuming that all other conditions stay unchanged.

$$
\begin{aligned}
& \Delta \mathrm{V}=\mathrm{S}_{\mathrm{Q}} \Delta \mathrm{Q} \\
& \Delta \mathrm{V}=\mathrm{S}_{\mathrm{P}} \Delta \mathrm{P}
\end{aligned}
$$

Adjusting the elements of $\Delta \mathrm{Q}$ and $\Delta \mathrm{P}$ over a range from $0-1.0 \mathrm{pu}$, one by one, enables the corresponding columns of the sensitivity matrix to be obtained by simulation. The $\mathrm{S}_{\mathrm{Q}}$ matrix describes the reactive power injection at node $j$,
$\Delta \mathrm{Q}_{\mathrm{j}}$, which is required to change the node $i$ voltage $\Delta \mathrm{V}_{\mathrm{i}}$. It follows that, for a desired change of voltage at node $i$, the reactive power injections at all other network nodes can be determined from equation (IV.4). Equivalent equation (IV.5) is also presented for active power injections.

$$
\begin{gathered}
\Delta \mathrm{V}_{\mathrm{i}}=\mathrm{s}_{\mathrm{Q}_{\mathrm{i} 1}} \Delta \mathrm{Q}_{1}+\cdots+\mathrm{s}_{\mathrm{Q}_{\mathrm{ij}}} \Delta \mathrm{Q}_{\mathrm{j}}+\cdots+\mathrm{s}_{\mathrm{Q}_{\mathrm{in}}} \Delta \mathrm{Q}_{\mathrm{n}} \\
\Delta \mathrm{V}_{\mathrm{i}}=\mathrm{s}_{\mathrm{P}_{\mathrm{i} 1}} \Delta \mathrm{P}_{1}+\cdots+\mathrm{s}_{\mathrm{P}_{\mathrm{ij}}} \Delta \mathrm{P}_{\mathrm{j}}+\cdots+\mathrm{s}_{\mathrm{P}_{\mathrm{in}}} \Delta \mathrm{P}_{\mathrm{n}}
\end{gathered}
$$

The $s_{Q}$ and $s_{P}$ coefficients in equation (IV.4) and (IV.5) are elements of the respective matrices $S_{Q}$ and $S_{P}$.

A merit order is then used to ensure that the generators with the greatest effect on node $i$ voltage adjust their reactive power injections to bring node $i$ voltage within limits, taking account of the voltage and reactive power limits of the relevant machine/machines. The proposed method, with its flexibility in selecting the reactive power required from each unit to support the voltage profile, is ideal for on-line application. This is demonstrated using the DIgSILENT PowerFactory [2] software.

\section{TEST CASE}

To demonstrate the reactive power control technique, a test feeder with challenging voltage management issues is utilized - see Figure 2. It is based on the IEEE 13-bus Test Feeder [1], characterised by some very low voltages under heavy-load conditions. This LV feeder consists of overhead and underground lines, with loads typical of distributed networks. Commonly used voltage support equipment [5], and an in-line transformer, are included in the model. For present purposes the test feeder was balanced by splitting the total loading at each site equally over the three phases; single- and double-phase lines were replaced with threephase lines. Five DG units have been added, as shown in Figure 2. Three of these networks were then daisy-chained.
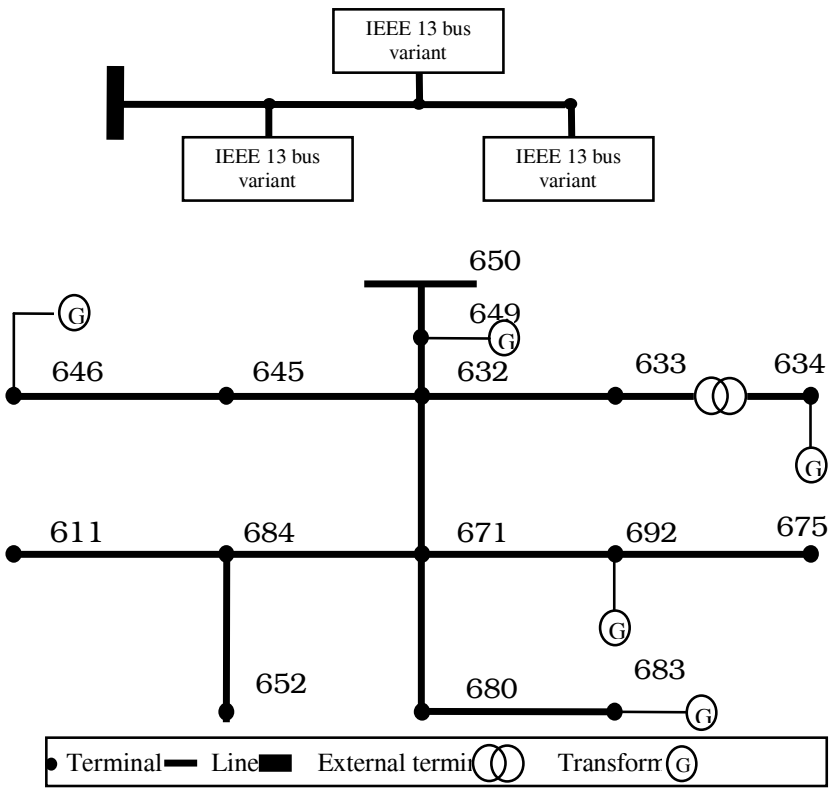

Figure 2: Test network. The upper diagram shows the overall test network. The lower diagram shows the IEEE 13-bus model and DG locations. 


\section{RESULTS}

Initial testing prior to the addition of the DG confirmed that the balanced network exhibits extreme voltages. The network, in its present condition, has no reactive power correction equipment or generation. Thus all the active and reactive power is supplied by the external grid. To supply the network demand and the associated losses, the external grid supplies 6.35 MW, 6.60 MVAr. With load primarily connected to the extremities of the IEEE 13-bus feeder it follows that large power flows occur in the main feeder conductors as reported in [7]. Overall the large power flows from the grid supply point to the peripheral nodes cause large voltage sags and losses of $1.06 \mathrm{MW}, 3.38 \mathrm{MVAr}$. Voltages at the nodes are observed to range from 0.530 to 1.000 per unit; only the grid node, 650 , is held within the allowed range of 0.95 to 1.05 per unit (Figure 3 ). The operator is required to provide support to ensure that voltages are within this range. Traditionally, static VAr compensation, tap-changing transformers and capacitive compensation would be used to achieve this.

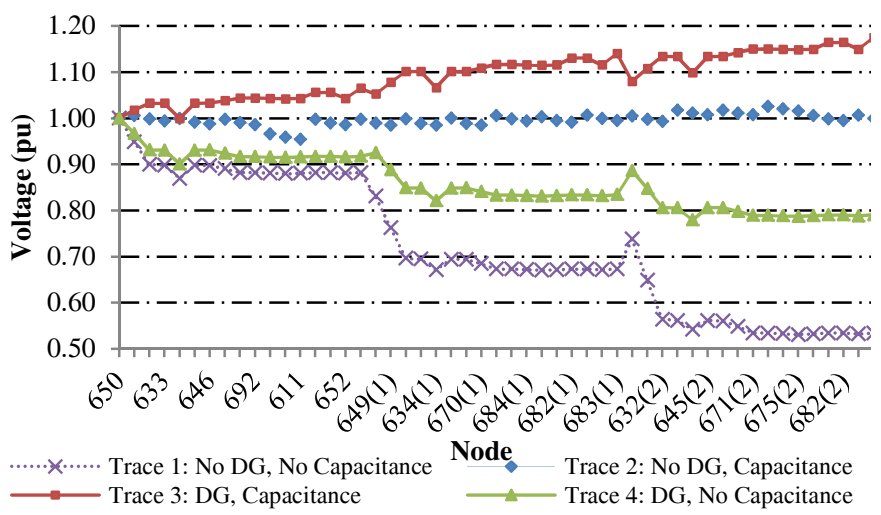

Figure 3: Test feeder voltage profile with/without reactive compensation.

\section{B. Traditional network support}

Capacitor placement is now used to bring the voltage within statutory limits. Applying the "Optimum capacitor placement" function within DIgSILENT it is observed that shunt capacitance of $1.70 \mathrm{MVAr}$ is placed at node 683, 1.80 MVAr at nodes $683(1)$ and $683(2)$ with a further 0.10 MVAr at nodes 643, 634 (1) and 634 (2). This source of reactive power reduces the dependency on the external grid, thus reducing conductor congestion around the external network. The power losses decreased by $61.3 \%$ to 0.410 MW, 1.310 MVAr and the mean loading of conductors dropped by $4.52 \%$ to $22.62 \%$ of their thermal limits. Moreover, the reactive power support brings the voltage within the statutory limits, with voltage ranging from 0.954 to 1.026 per unit with a mean value of 0.997 per unit - see trace 2 of Figure 3. Hence it is seen that traditional methods can support the voltage of the distribution network, in the absence of DG, reducing dependence on the external network and freeing the capacity of network assets.

\section{Distributed Generation $P Q$ Characteristics}

The impact of five 1.25-MVA, 1-MW wind turbine generators (WTGs) is now considered. Their locations are shown in Figure 2. Each WTG has a full-load power factor of 0.8 lagging, i.e. absorbing reactive power of $0.75 \mathrm{MVAr}$.
It is assumed for the purposes of this paper that capacitive shunt compensation of $0.75 \mathrm{MVAr}$ is available, thus enabling the WTGs to operate at unity power factor at full load. The assumed capability chart is shown in Figure 4. It should be noted that the WTG with the assumed capacitive compensation fulfils the requirements of most Distribution Codes, where a power factor of at least 0.95 is required [9].

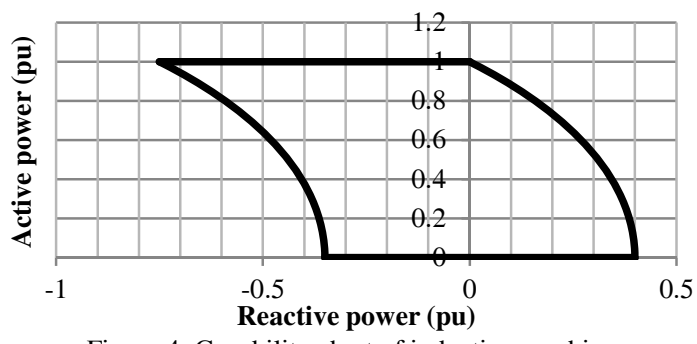

Figure 4: Capability chart of induction machine.

\section{Effect of distributed generation}

Connecting five WTGs, as indicated in Figure 2, highlights the need for control as DG is added to the network. It is assumed each generator has an output of $0.3 \mathrm{MW}$ and $0 \mathrm{MVAr}$, to represent the average export from a WTG with capacitive compensation. The network voltages can be observed to rise, as one would expect from the injection of active power into the network. The voltages are within the range 1.000 to 1.175 per unit, with an average of 1.094 per unit, as may be observed in trace 3 of Figure 3, with the original network's reactive power support still connected.

If reactive power support is not reduced from the network, the statutory voltage limits of (II.2) will not be met. However, if the reactive power support is removed completely, the other extreme is observed, where most of the network voltages are on the lower side of the statutory limit, ranging from 0.779 to 1.000 per unit, with an average value of 0.858 per unit - see trace 4 of Figure 3 . Therefore, control of the network support is essential. The stochastic nature of renewable energy DG increases complexity.

Operating the network efficiently becomes a major challenge, one which increases in complexity with augmented DG penetration. With small amounts of DG penetrating the distribution network the losses can be reduced. However, as the capacity of DG increases, the local load is met by the surrounding generation. As further generation is accommodated onto the network the power flows will reverse, leading to increased congestion as the network exports increasing power to the grid. Typically, small DG (DG $<5 \mathrm{MW}$ ) will operate at unity or as close to unity power factor as possible to maximise active power output and hence revenue. Indeed some DG must operate at unity power factor due to the inverters that couple the unit to the network [10]. Inverters are, however, frequently capable of allowing variable power factors and indeed allow for control of the DG's point of connection voltage [11].

\section{E. Traditional network support with DG connected}

If all connected DG has controllable $\mathrm{P}$ and $\mathrm{Q}$, as is the case for synchronous machines and inverter-connected DG, the optimum capacitor placement could be obtained for the given power output. For the connected generation 
configuration the optimum capacitor placement would require a $1.20 \mathrm{MVAr}$ capacitor placed at node 683 with 1.15 and 1.12 MVAr at nodes 683 (1) and 683 (2) respectively, while the reactive support at nodes 634, 634(1) and 634(2) remains at 0.1 MVAr. Such support would ensure that voltages range from 0.975 to 1.024 per unit with a mean voltage of 1.008 per unit, as observed in trace 3 of Figure 5.

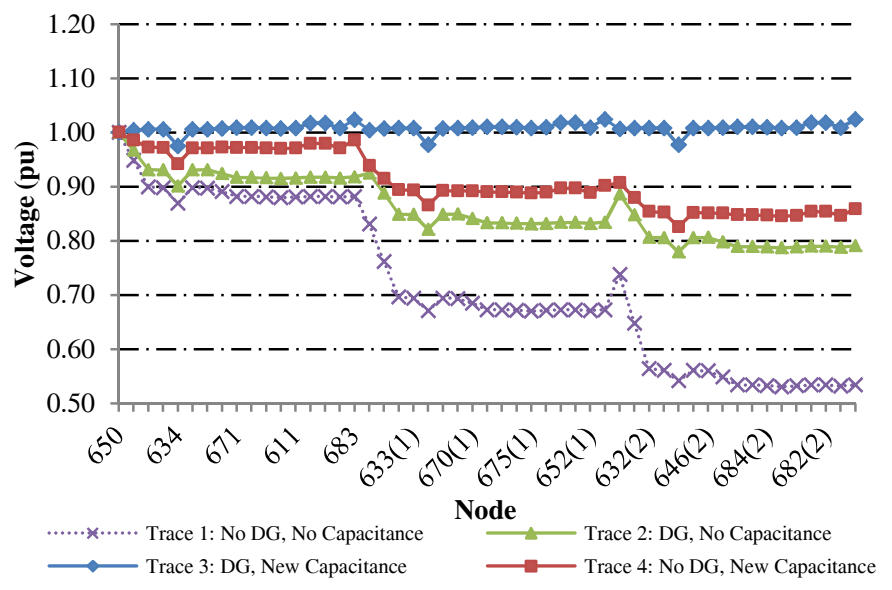

Figure 5: Voltage profile for the test feeder with network reactive compensation re-dispatched.

With the local voltage support provided by the capacitors and the load being met by the local generators, the average congestion on the network is reduced further to $11.80 \%$ of the conductors' thermal limits. Consider the new capacitor placement: if the DG portfolio is of the same type of generator, wind for example, there may be occurrences when there is no DG power. In such circumstances, and if reactive assets on the network are uncontrollable but remain in situ, the voltage would drop to between 0.834 and 1.000 per unit, as seen in trace 4 of Figure 5.

\section{F. Proposed network support with DG control}

For the given test network, dispatching the generators with the control algorithm gives acceptable voltage profiles as shown by traces 3 and 4 of Figure 6 . In trace 3 the existing reactive power support is completely removed from the network. The sensitivity control algorithm dispatches the DG such that the voltages are within the range 0.954 to 1.000 per unit. This is achieved by exporting $0.35 \mathrm{MVAr}$ of reactive power from generators connected to nodes 634, 634 (1), 634 (2), 646, 646 (1), 646 (2), 692, 692 (1), and 692 (2). These result in a further reduction in the mean loading of conductors to $10.59 \%$ of their thermal limits and reduced network losses of $0.028 \mathrm{MW}, 0.079 \mathrm{MVAr}$. By contrast, when the original reactive power support remains connected the control algorithm dispatches the generation such that DG connected to nodes 692, 692 (1), and 692 (2) absorb $0.35 \mathrm{MVAr}$ and those connected to nodes 683, 683 (1), and 683 (2) absorb 0.3 MVAr. This ensures that the voltages are within the range 0.967 and 1.045 per unit. These result in a mean conductor loading of $12.85 \%$ of their thermal limits and lower losses of 0.057 MW, 0.172 MVAr.

The results indicate that the sensitivity control algorithm can use the available reactive power from the DG connected to the network to maintain the network's voltage profile within the desired range. The results also suggest that dispatching reactive power from DG, when compared to traditional network support, can reduce network losses whilst allowing for greater DG penetration on the network.

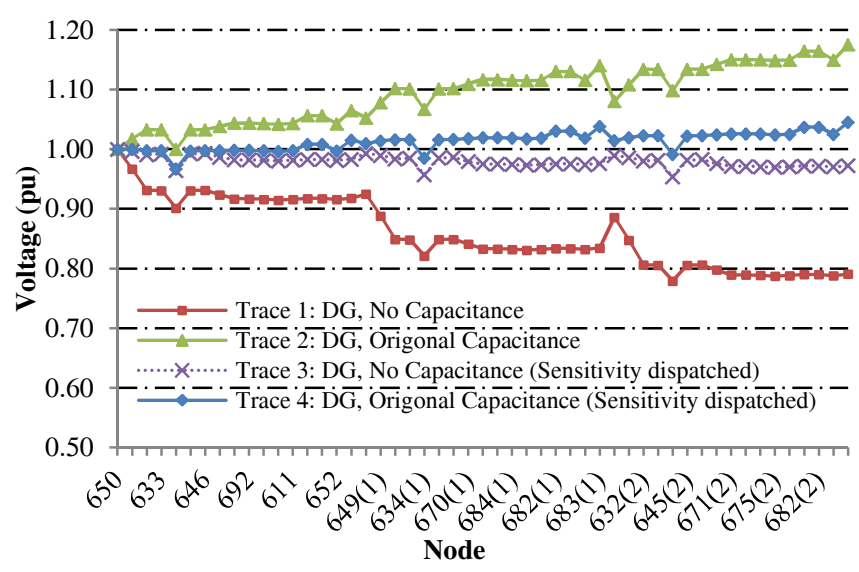

Figure 6: Voltage profile for control technique.

\section{G. Worst case senarios}

Of particular interest is the impact of distributed generation on the demand for reactive power from the grid. Three key scenarios are presented and examined:

- Minimum demand, maximum generation - most likely to cause the maximum feeder voltage rise.

- Maximum demand, no generation - most likely to cause the lowest feeder voltages.

- Maximum demand, maximum generation would typically cause increased demand for reactive power from the network.

Figure 7 presents the voltage profiles for the three scenarios when the DG is dispatched at unity power factor and then using the sensitivity control algorithm. Table 1 presents the reactive power support from the external network (Q MVAr), the number of voltages in range (V, up to 51 nodes) and network losses (L MW). Subscript PF denotes DG operated at unity power factor; subscript Senc denotes DG dispatched by the sensitivity control algorithm.

A potential problem is that distribution networks may draw excessive reactive power from the transmission network, resulting in system-wide voltage collapse.

Table 1: Reactive power support from the external network, number of voltages in range and network losses for three scenarios

\begin{tabular}{|c|c|c|c|c|c|c|}
\cline { 2 - 7 } \multicolumn{1}{c|}{} & $\mathbf{Q}_{\mathbf{P F}}$ & $\mathbf{Q}_{\text {senc }}$ & $\mathbf{V}_{\mathbf{P F}}$ & $\mathbf{V}_{\text {senc }}$ & $\mathbf{L}_{\mathbf{P F}}$ & $\mathbf{L}_{\text {senc }}$ \\
\hline Max. demand, no DG & 6.60 & -1.35 & 1 & 51 & 1.06 & 0.36 \\
\hline Min. demand, max. DG & 6.57 & 6.91 & 42 & 51 & 2.06 & 2.07 \\
\hline Max. demand, max.DG & 6.96 & 3.16 & 16 & 51 & 1.18 & 0.49 \\
\hline
\end{tabular}

When the distribution network has maximum demand and minimum generation only the external grid node remains within the required voltage range when the DG is dispatched at unity power factor. Losses are $1.06 \mathrm{MW}$, with the external network supplying 6.60 MVAr of reactive power to support network voltages. By contrast, when DG is dispatched by the sensitivity control algorithm all network voltages are within the desired range. The network losses are reduced by $66 \%$; the dependence for reactive power from the transmission network is eliminated, with the distribution network now exporting 1.35 MVAr of reactive power. 

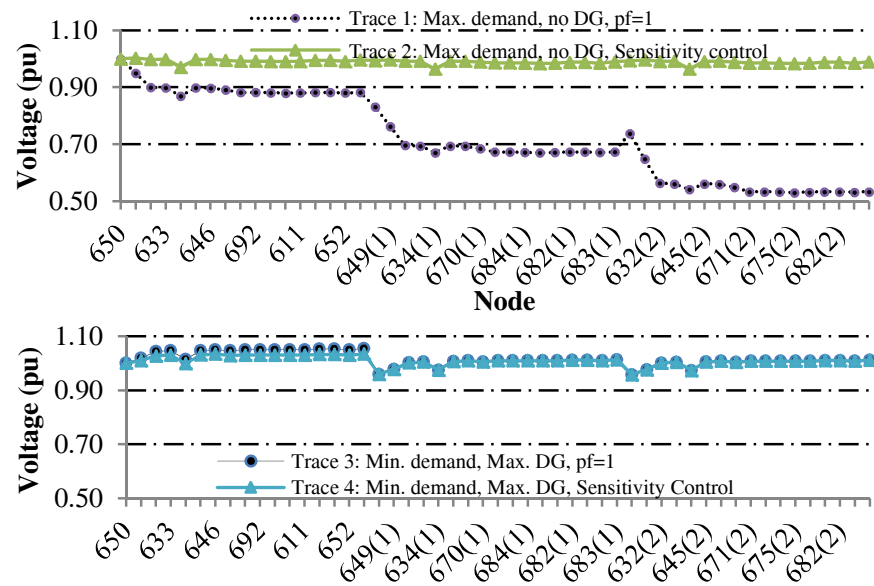

Node

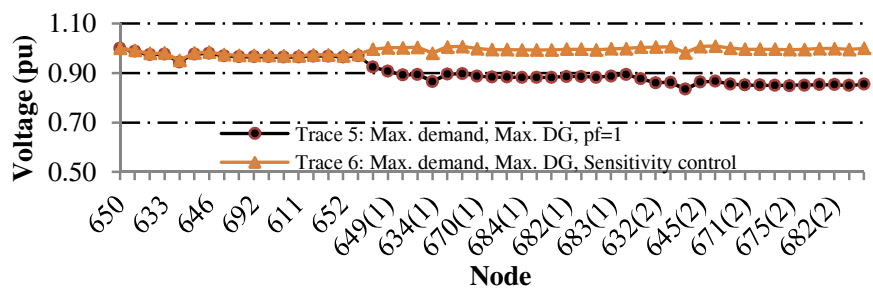

Figure 7: Voltage profiles for three test conditions.

The reactive power required from the grid with maximum demand and generation is reduced. Losses decrease by $58 \%$ while the reactive power drawn from the grid is down by $55 \%$ - critical, with reactive resources fully stretched.

Reduced dependence on the grid for reactive power did not occur with minimum demand and maximum DG generation. The sensitivity dispatch draws more reactive power to bring network voltages within range. However, at minimum demand reactive resources are plentiful.

So far the sensitivity control algorithm has dispatched DG solely to keep voltages within range. However, the sensitivity control algorithm could be developed to reduce distribution network demand for reactive power from the grid. Consider again the minimum demand maximum generation scenario. In this case 9 voltages were outside the allowed range. This required generator 692 to absorb $0.3 \mathrm{MVAr}$ to bring all voltages within range. An additional $0.3 \mathrm{MVAr}$ (0.34 MVAr when including the associated reactive power losses) was then supplied by the grid, increasing losses. However, if the merit order also considered the reactive power drawn from the grid, a dispatch with a net export of 0.4 MVAr would bring the voltages within range, albeit with a higher average. Losses were $1.96 \mathrm{MW}$, with the grid supplying 5.95 MVAr, 9\% less than when operating at unity power factor.

\section{CONCLUSIONS}

A control scheme has been proposed that dispatches reactive power from individual DG units on a close to realtime basis. When the central controller detects that voltages are out of range, it requests local DG to increase/decrease reactive or active power. The voltage problems may be acute when much of this generation is renewable, with variable active power output un-correlated with consumer demand.
The reactive and active power commitment is based on a sensitivity factor, so that the DG with the greatest effect on the problematic nodes is selected on a merit order. If all DG control has been exhausted, the controller will then consider flexible loads to help support the network; again, the load yielding maximum system benefit is selected first.

It has been shown that the procedure achieves its primary objective of bringing voltages within the defined limits. It could also be used to reduce the reactive power demand of the distribution network on the grid and active power losses.

The technology - real-time communication of network data and controllable DG reactive power - exists for such a scheme. However, the greatest issue is that DG owners have little incentive to help solve network problems. Therefore, it is essential to establish a reward mechanism to encourage reactive power variation from DG, with the objective of ensuring a reliable and effective system.

\section{REFERENCES}

[1] IEEE Distribution Planning Working Group Report: "Radial distribution test feeders", IEEE Transactions on Power Systems, Vol. 6, No. 3, pp. 975-985, 1991

[2] DIgSILENT GmbH. Available online at DIgSILENT web site: http://www.digsilent.de/ - Last accessed 09 October 2012.

[3] J.A.P. Lopes: "Integration of dispersed generation on distribution networks - impact studies", Power Engineering Society Winter Meeting, Vol.1, pp. 323-328, 2002.

[4] P.N. Vovos, A.E. Kiprakis, A.R. Wallace and G.P. Harrison: "Centralized and distributed voltage control: impact on distributed generation penetration", IEEE Transactions on Power Systems, Vol. 22, No. 1, pp. 476-483, 2007.

[5] Scottish and Southern Energy PLC: "Long-term development statement for Scottish Hydro Electric Power Distribution plc's electricity distribution system", 2011.

[6] B. M. Weedy et al.: Electric Power Systems. Wiley, New York, 2012.

[7] S.R. Abbott, B. Fox and D.J. Morrow: "Coordinated control of generation for MV network voltage management", Powertech 2013.

[8] S.R. Abbott, B. Fox and D.J. Morrow: "Distribution network voltage support using sensitivity-based dispatch of distributed generation", PES 2013 GM, Vancouver, 2013.

[9] Northern Ireland Electricity PLC, "Distribution Code," 2010. http://www.nie.co.uk/documents/Connections/Distribution_Code_1_ May_2010.aspx - Last accessed 13 February 2013.

[10] SMA Solar Technology: "Inverter for wind energy power plants", Windy Boy 2500 Technical Information, 2012.

[11] SMA Solar Technology: "Inverter for wind energy power plants", Windy Boy 5000TL Technical Information, 2012. http://files.sma.de/d1/2485/WINDYBOY-KEN110514W.pdf.

\section{BIOGRAPHIES}

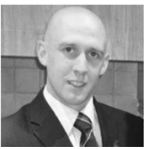

Stephen Abbott received a $1^{\text {st }}$ class MEng Honours degree from QUB in 2009. He is currently pursuing a $\mathrm{PhD}$ at QUB. His research interests include distributed generation, reactive power and dynamic line rating.

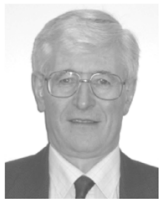

Brendan Fox received the B.Sc. and Ph.D. degrees from QUB in 1966 and 1969. Following a period with the Central Electricity Generating Board in Great Britain, he joined the Ulster Polytechnic in 1972. He was then appointed to a lectureship at QUB in 1980, where he is now an Emeritus Professor, with research interests in wind power integration.

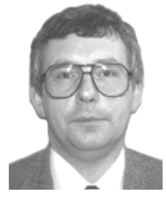

D. John Morrow (M'00) received the B.Sc. and Ph.D degrees from QUB in 1982 and 1987 respectively. He is a Professor in electrical engineering at QUB, with research and consulting interests in electric power systems, power system instrumentation and embedded generation. Prof. Morrow is a member of the IET and also a member of the IEEE PES Excitation Systems Subcommittee. 